\title{
Preparation, Physico-chemical Characterization and Photocatalytic Properties of Se Doped $\mathrm{TiO}_{2}$ Nanoparticles
}

\author{
SIMONA CAVALU ${ }^{*}$, SIMONA VICAS ${ }^{2}$, TRAIAN COSTEA $^{3}$, LUMINITA FRITEA ${ }^{1}$, DANA COPOLOVICI ${ }^{4}$, \\ VASILE LASLO ${ }^{2}$ \\ ${ }^{1}$ University of Oradea, Faculty of Medicine and Pharmacy, 101 Decembrie Sq., 410081 Oradea, Romania \\ ${ }^{2}$ University of Oradea, Faculty of Environmental Protection, 26 Gen. Magheru Str., 410048, Oradea, Romania \\ ${ }^{3}$ University of Oradea, Industrial Engineering Doctoral School, 1 University Str., 410087, Oradea, Romania \\ ${ }^{4}$ Aurel Vlaicu University of Arad, Faculty of Food Engineering, Tourism and Environmental Protection, Institute of Research, \\ Innovation and Development in Technical and Natural Sciences, 2 Elena Dragoi Str., 310330, Arad, Romania
}

Selenium-doped titania nanoparticles were prepared and characterized from physico-chemical and morphological point of view, with the aim possible applications in photocatalysis. DLS measurement indicated that $\mathrm{TiO}_{2}$ particles presents two different components: the first one, with low concentration and maximum size distribution at about $20 \mathrm{~nm}$, and second one, with high concentration and size distribution ranging from 40 to $250 \mathrm{~nm}$ (maximum at $100 \mathrm{~nm}$ ). After doping procedure and thermal treatment at $800^{\circ} \mathrm{C}$, the size distribution reveals the formation of nanoparticles with wide range of diameters, from $20 \mathrm{~nm}$ to $500 \mathrm{~nm}$, with good stability, as demonstrated by Zeta potential values: - $19 \mathrm{mV}$ for $\mathrm{TiO}_{2}$ and $-25 \mathrm{mV}$ for $\mathrm{Se}_{\mathrm{TiO}}$ particles. Ti-O-Ti and $\mathrm{Se}$-O vibrational modes were identified in ATR FTIR spectra. As a consequence of thermal treatment at $800^{\circ} \mathrm{C}$, morphological changes of titania particles from nanorodes to nanowires were observed. The XRD spectrum of $\mathrm{TiO}_{2}$ starting material shows the typical crystalline pattern of anatase (tetragonal), in good agreement with the standard diffraction data, while a mixture of anatase and rutile (tetragonal) was obtained after the annealing process. The results of photocatalytic activity test demonstrated that both $\mathrm{TiO}_{2}$ and $\mathrm{Se}$-doped $\mathrm{TiO}_{2}$ nanoparticles can effectively decompose methylene blue under the visible light irradiation, but with Se doping, the photocatalytic capability is significantly improved.

Keywords: selenium, titania, nanoparticles, SEM, DLS, FTIR, photocatalysis

Nanosized titania has been intensively used in the last decades due to its special chemical and physical properties compared with the bulk. Many possible applications such as gas sensing, electronic devices, photovoltaic cells, heterogeneous catalysis, photocatalysis and lithium batteries [1-5] have been investigated. Until now, $\mathrm{TiO}_{2}$ nanostructures of nanotubes, nanorods and nanowires, or nanosheets have been fabricated by various techniques, including sol-gel and hydrothermal techniques or microwave- solvo-thermal method [6, 7]. Moreover, titanium dioxide-associated photocatalysis under ultraviolet (UV) irradiation was investigated as a strategy for developing bioactivity and antibacterial properties on biomaterials [7]. Titanium dioxide is considered very close to an ideal semiconductor for photocatalysis because of its high stability, low cost and safety toward both humans and the environment. For the first time, Matsunaga et al. [8] reported the photocatalytic activity of $\mathrm{TiO}_{2}$ as an effective microbiocide at photokilling Lactobacillus acidophilus, Saccharomyces cerevisiae and Escherichia coli. However, phototoxicity caused by photocatalytic activity may differ between anatase and rutile nanoparticles [9]. On the other hand, environmental applications, including photocatalytic treatment of wastewater, pesticide degradation and water splitting by $\mathrm{TiO}_{2}$ to produce hydrogen are extensively reported in research studies $[1,10]$.

Anatase $\mathrm{TiO}_{2}$ is considered to be the active photocatalytic component based on charge carrier dynamics, chemical properties and the activity of photocatalytic degradation of organic compounds. Previously research studies demonstrated that heat treatment is crucial in the synthesis of particles, being the most important factor regarding morphology, crystallinity and porosity modifications. For example, Wang et al. [11] investigated the relationship between the phase transformation and photocatalytic activity of nanosized anatase powder. They pointed out that, once the rutile phase $\mathrm{TiO}_{2}$ formed separately, the photocatalytic activity began to decrease rapidly.

In order to enhance the photocatalytic properties of $\mathrm{TiO}_{2}$, especially in the visible light range, ion doping was considered to be an efficient approach [12]. So, many elements were doped into $\mathrm{TiO}_{2}$, such as silver, iron, nitrogen, sulphur, carbon, boron, aiming to decrease the band gap energy and enhance the photocatalytic activity of $\mathrm{TiO}_{2}$. An interesting approach was reported by doping selenium into anatase $\mathrm{TiO}_{2}$ by various methods, with narrowed band gap energy and effectively extended absorption to the visible light range [13-15].

*email: simona.cavalu@gmail.com 
The aim of our work was to prepare and characterize selenium doped titania nanoparticles for improved photocatalytic performances, with potential application in organic dyes and pollutants in wastewater.

\section{Experimental part}

Preparation of Se-doped Ti nanoparticles

Hydrothermal reaction method was applied for the production of Se-doped $\mathrm{TiO}_{2}$ nanoparticles, according to Zavala et al [16] and Liu et al [17].Briefly, $7 \mathrm{~g}$ of $\mathrm{TiO}_{2}$ power (Sigma-Aldrich, CAS No-13463-76-7) was dissolved in $70 \mathrm{~mL} \mathrm{NaOH} 10 \mathrm{~N}$, by continuously stirring at $30^{\circ} \mathrm{C}$, for 2 hours. The solution was introduced in autoclave at $1400^{\circ} \mathrm{C}$ for 24 hours. The supernatant was removed and the $\mathrm{TiO}_{2}$ particles were washed with $\mathrm{HCl} 0.1 \mathrm{~N}$, until the $p \mathrm{H}=7$ was reached, followed by followed by centrifugation at $6000 \mathrm{r} / \mathrm{min}$ for 5 minute. Finally, the particles were washed three times with ultrapure water and dried at $80{ }^{\circ} \mathrm{C}$ during 18 hours. The calcination of $\mathrm{TiO}_{2}$ particles was performed in standard furnaces (Nabertherm $\mathrm{GmbH}$ ) at $800{ }^{\circ} \mathrm{C}$ for 2 hours. The resulted particles were allowed to react with a mixture of $\mathrm{HNaO}_{3} \mathrm{Se}$ (Alfa Aesar 96\%), $10.000 \mathrm{ppm}$ and lactose monohydrate (VWR Chemicals) in a molar ratio 1:3. The final mixture was heated at $100{ }^{\circ} \mathrm{C}$ until the characteristic red color was achieved, as an indicator of Se nanoparticles formation [18]. The resulted particles were washed three times with deionized water, filtered and dried at room temperature.

\section{Structural and morphological characterization of Se-doped $\mathrm{TiO}_{2}$ nanoparticles.}

The $\mathrm{TiO} 2$ particles obtained by calcination at $800^{\circ} \mathrm{C}$ and $\mathrm{Se}$-doped $\mathrm{TiO} 2$ particles obtained by hydrothermal reaction were characterized by dynamic light scattering(DLS), Fourier Transform Infrared Spectroscopy (ATR-FTIR), X-rays diffraction pattern (XRD) and scanning electron microscopy (SEM). DLS was applied to selenium nano-colloidal sol using ZEN 3690(Malvern Instruments) in order to determine the average particle size, size distribution and Zeta potential. In order to reveal the X-ray profile, analyses of the samples we used a X-ray diffractometer (MiniFlex 600, Rigaku, Japan). The following conditions were used for analyses: $40 \mathrm{kV}, 15 \mathrm{~mA}$, with $\mathrm{CuK} \alpha$ monochromatic radiation, SC-70 detector and an automatic sample changer (ASC-6). The scan range was $5^{\circ}-60^{\circ}$, with step width $0.02^{\circ}$, scan speed $5^{\circ} / \mathrm{min}$, at room temperature. The PDXL2 Version 2.4.2.0 containing powder diffraction analysis package (PDXL Comprehensive Analysis) was used to analyze and calculate the lattice strain and crystallite size with Halder-Wagner method. The powder samples were investigated by FTIR in the range $400-4000 \mathrm{~cm}^{-1}$, using Spectrum BXII spectrophotometer (PerkinElmer), equipped with MIRacle ATR accessory (ZnSe crystal), at scanning speed of $32 \mathrm{~cm}^{-1}$ and spectral width $2.0 \mathrm{~cm}^{-1}$. Morphological details of the $\mathrm{TiO}_{2}$ nanoparticles and Se-doped $\mathrm{TiO}_{2}$ nanoparticles were investigated using the scanning electron microscope Leo 438VP SEM, with variable vacuum capability (maintained at low value).

\section{Photocatalytic activity test}

The test developed in this study, further referred to as the 'standard test', was a dye degradation test. The photocatalytic activity was evaluated in aqueous solution, by using methylene blue as a model chemical, in batch photoreactor, under UVlight irradiation with 400W Kr lamp (Osram). The illumination power of the lamp was mainly in the UV-A region. The photochemical reactor was a beaker containing suspension of nanoparticles solution and methylene blue which was placed in a continuously ventilated chamber. $0.9 \mathrm{~g}$ of photocatalyst was mixed with $180 \mathrm{~mL}$ methylene blue solution $(8 \mathrm{mg} / \mathrm{L}) \mathrm{with}$ continuous stirring. The distance between the lamp and the reactor was $20 \mathrm{~cm}$. After scheduled time interval (30 minutes), $4 \mathrm{~mL}$ solution was collected for spectral analysis and monitored by using a UV-vis spectrophotometer (Shimadzu UV-VIS 1700 Pharma Spec).

\section{Results and discussions}

Immediately after the thermal reaction, the colloidal sol of $\mathrm{TiO}_{2}$ particles respectively Se-doped $\mathrm{TiO}_{2}$ particles was analyzed by dynamic light scattering (DLS) in order to evaluate the particles size distribution and apparent Zeta-potential, data being presented in Fig. 1. One can observe that $\mathrm{TiO}_{2}$ particles present two different components: the first one, with low concentration and maximum size distribution at about $20 \mathrm{~nm}$, and second one, with high concentration and size distribution ranging from 40 to $250 \mathrm{~nm}$ (maximum at $100 \mathrm{~nm}$ ). After doping procedure and thermal treatment at $800^{\circ} \mathrm{C}$, the size distribution reveals the formation of nanoparticles with wide range of diameters, from $20 \mathrm{~nm}$ to $500 \mathrm{~nm}$ (maximum at 180 $\mathrm{nm}$ ). Three repeated measurements were performed for each sample. The corresponding Zeta-potential was $-19 \mathrm{mV}$ for $\mathrm{TiO}_{2}$ and $-25 \mathrm{mV}$ for $\mathrm{Se} / \mathrm{TiO}_{2}$ particles. These values indicates a good stability, especially for $\mathrm{Se} / \mathrm{TiO} \mathrm{O}_{2}$ nanoparticles. It is well known that the criteria of nanoparticles stability is correlated with the values of zeta potential ranged from higher than $+20 \mathrm{mV}$ to lower than $-20 \mathrm{mV}[19]$. 


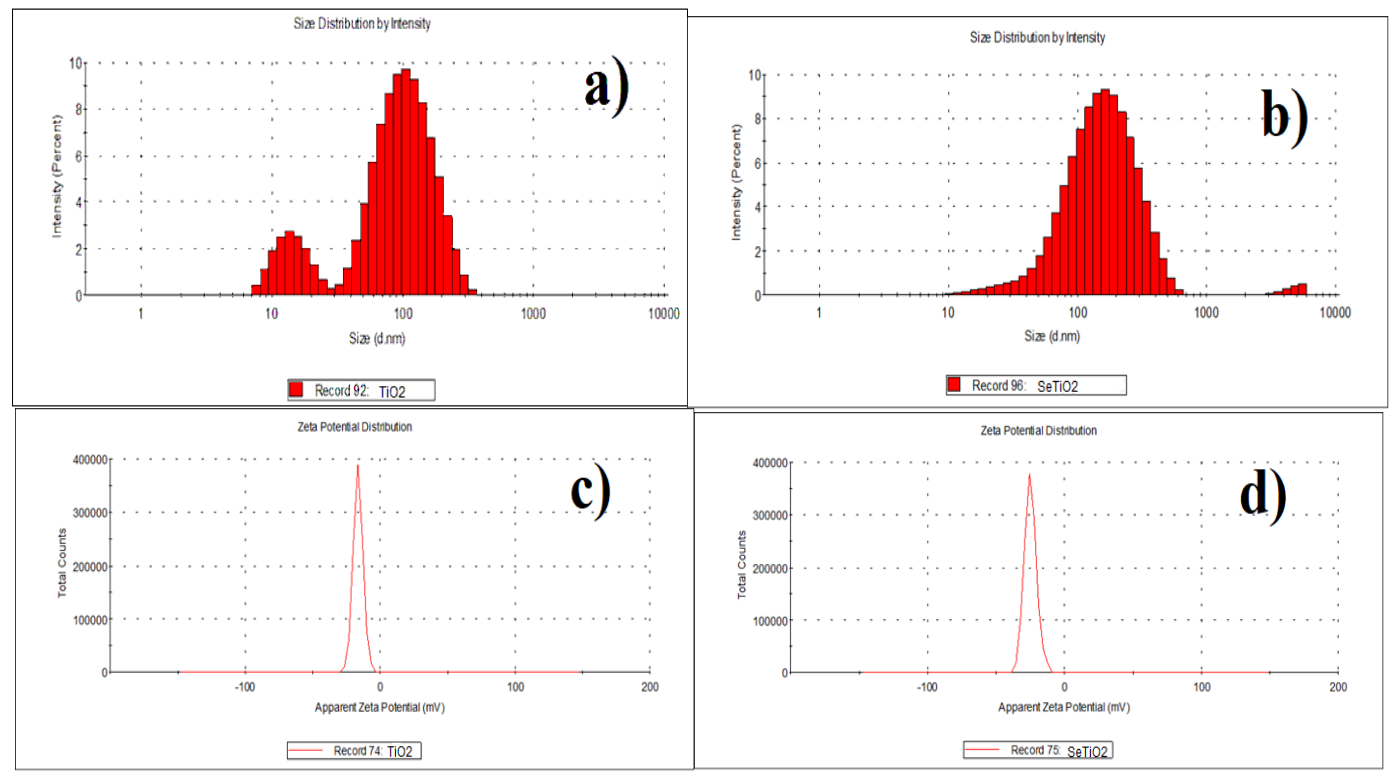

Fig. 1 Size distribution measurement (a, b) and apparent Zeta potential records (c, d) for $\mathrm{TiO}_{2}$ and $\mathrm{Se} / \mathrm{TiO} 2$ particles.

The calcinated samples at $800{ }^{\circ} \mathrm{C}$ were analyzed from structural point of view by ATR-FTIR spectroscopy and the spectra are displayed comparatively in figure 2.

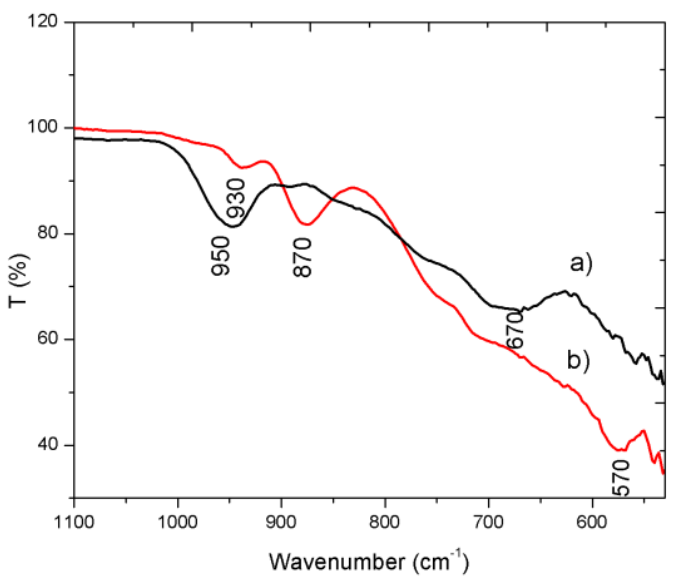

Fig. 2 ATR-FTIR spectra of powder samples after 2 hours calcination at $800{ }^{\circ} \mathrm{C}$ : a) $\mathrm{TiO}_{2}$ particles; b) Se doped $\mathrm{TiO}_{2}$ particles

It was previously reported that the spectral region from 1000 to $400 \mathrm{~cm}^{-1}$ is ascribed to the Ti-O stretching and Ti-O-Ti bending vibrational modes in anatase [20]. So, we can assign the band at $950 \mathrm{~cm}^{-1}$ to Ti-O-Ti stretching vibrations in $\mathrm{TiO}_{2}$ particles, while the broad band at $670 \mathrm{~cm}^{-1}$ is assigned to banding vibration. After doping procedure, the stretching vibration of Se-O bonds are observed as a distinct band at $870 \mathrm{~cm}^{-1}$ and the bending vibration is visible at $570 \mathrm{~cm}^{-1}$, which corresponds to the vibrational features of the commercial selenium nanoparticles powder [21]. In the same time, the intensity of Ti-OTi stretching vibrations are drastically reduced concomitant with a shift to lower wavenumber, at $930 \mathrm{~cm}^{-1}$, as shown in Fig.2(b).

The morphological features of $\mathrm{TiO}_{2}$ and Se-doped $\mathrm{TiO}_{2}$ particles obtained after calcination at $800^{\circ} \mathrm{C}$ are displayed in Figure 3.

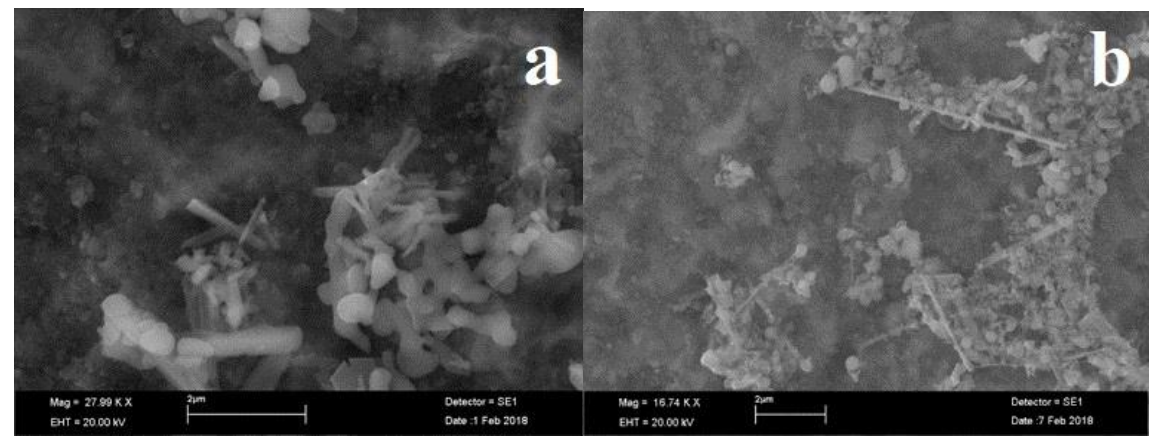

Fig. 3. SEM micrographs of $\mathrm{TiO}_{2}$ particles (a) and Se-doped $\mathrm{TiO}_{2}$ particles 
One can observe that $\mathrm{TiO}_{2}$ particles present a rode- shaped structure with diameter of about $150 \mathrm{~nm}$ and variable length, agglomerated and randomly distributed (Fig. 3a). Upon the hydrothermal reaction and Se-doping of $\mathrm{TiO}_{2}$ particles, the formation of $\mathrm{TiO}_{2}$ nano-wires was noticed, with the diameter of about $80 \mathrm{~nm}$ and spherical Se nanoparticles with diameter of about $200 \mathrm{~nm}$, agglomerated, surrounding the $\mathrm{TiO}_{2}$ nano-wires. We have previously demonstrated the formation of spherical Se nanoparticles in a hydrothermal reaction, with diameter ranging from $55 \mathrm{~nm}$ to $290 \mathrm{~nm}$, depending on the reducing agent and reaction time [19]. In the present case, the spherical Se nanoparticles were produced in situ, as a consequence of doping process followed by annealing of $\mathrm{TiO}_{2}$ particles. In the same time, the morphological changes of titania particles from nanorodes to nanowires occurred as a consequence of annealing, which is not surprising. In the literature it is mentioned the formation of crystallized titania nanotubes/nanorods and their transformation into nanowires depending on the synthesis conditions in autoclave [22].

In order to identify the crystalline structure of $\mathrm{TiO}_{2}$ and $\mathrm{Se}$-doped $\mathrm{TiO}_{2}$ particles, XRD spectra were recorded and presented in Figure 4.
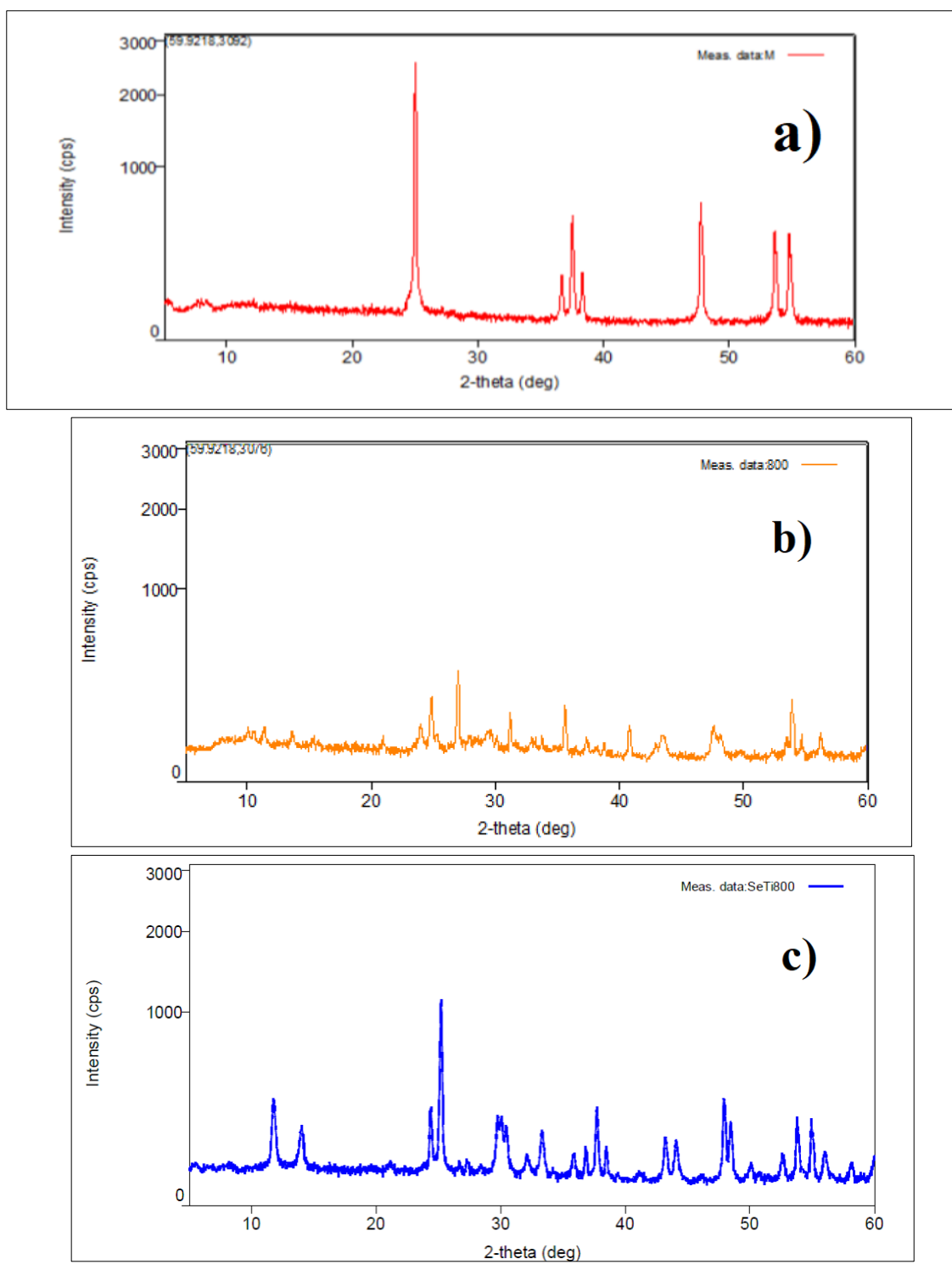

Fig. 4. XRD pattern of $\mathrm{TiO}_{2}$ starting material powder, as received from the supplier (a), $\mathrm{TiO}_{2}$ particles annealed at $800^{\circ} \mathrm{C}(\mathrm{b})$ and Se-doped $\mathrm{TiO}_{2}$ particles annealed at $800{ }^{\circ} \mathrm{C}(\mathrm{c})$

The XRD spectrum of $\mathrm{TiO}_{2}$ starting material (Fig. 4a) shows the typical crystalline pattern of anatase (tetragonal), with sharp two peaks from $24.99^{\circ}$ and $47.75^{\circ}$, in good agreement with the standard diffraction data, while a mixture of anatase and rutile (tetragonal) was obtained after the annealing process (Fig. 4b)[23]. The estimated average crystallite size was 535(6) and 143(2), respectively for starting material and annealed sample. After Se-doping of $\mathrm{TiO}_{2}$ particles, the XRD pattern is changed, as it is shown in Figure 4c, and the crystallite size was 230(14). The crystallite size and lattice strain normally influence the X-ray diffraction profiles. 
The results of photocatalytic activity test (standard test) are presented in figure 5, showing the typical time-dependent UV-Vis spectra of methylene blue solution by $\mathrm{TiO}_{2}$ and $\mathrm{Se}$ doped $\mathrm{TiO}_{2}$ in photochemical reaction. It can be seen that the intensity of the characteristic absorption peak of methylene blue solution decreases with time, in both cases, demonstrating that $\mathrm{TiO}_{2}$ and $\mathrm{Se}$-doped $\mathrm{TiO}_{2}$ nanoparticles can effectively decompose methylene blue under the visible light irradiation.

With Se doping, the photocatalytic capability is significantly improved, as can be seen comparing the absorption spectra in Fig. 5 (a) and (b).

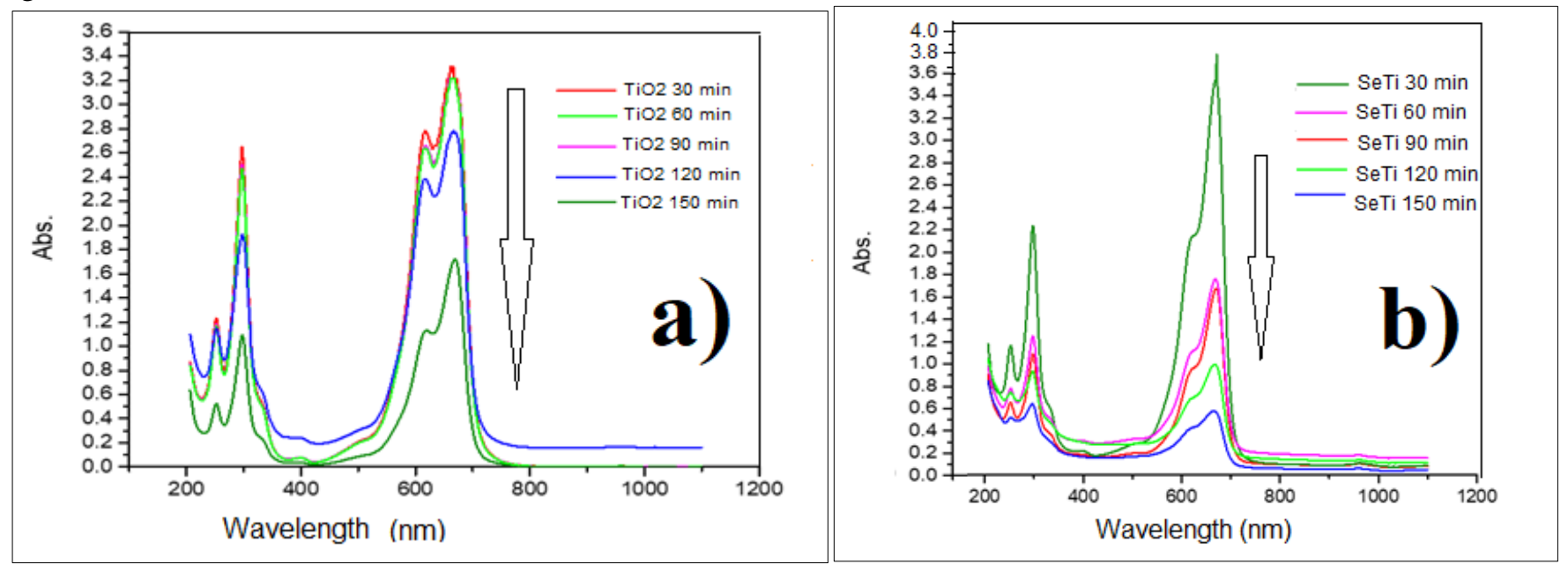

Fig. 5 Photocatalytic activity of $\mathrm{TiO}_{2}$ particles (a) and $\mathrm{Se}$ doped $\mathrm{TiO}_{2}$ particles in a standard test (methylene blue decomposition)

The photoinduced electrons and holes play important role in the photocatalytic reaction, by undergoing the following steps: 1) The electrons are adsorbed by $\mathrm{O} 2$ to produce superoxide radical anions of $\mathrm{O}^{2-} ; 2$ ) The holes can oxidize $\mathrm{OH}^{-}$to produce OH. 3) Both can further react with methylene blue which is decomposed to $\mathrm{CO}_{2}$ and $\mathrm{H}_{2} \mathrm{O}$. In a recent paper, W. Xie $\& a l$. explained the detailed reaction mechanism in a similar situation, concluded that improved photocatalytic activity of Se-doped $\mathrm{TiO}_{2}$ under visible light can be first understood by the decreasing band gap into the visible range with increasing Se doping concentration, which might increase the absorption efficiency of the visible light [15]. On the other hand, it is known that the photocatalytic activity of the $\mathrm{TiO}_{2}$ catalyst is highly dependent on crystal size and crystallinity [23, 24] Some other papers pointed out that the visible photocatalytic activity was decreased with the higher calcination temperature $\left(900^{\circ} \mathrm{C}\right)$. As a matter of facts, the highest photoactivity shown by the conditions can be due to the synergistic effects of higher surface area, lower crystal size and higher dopant content [24].

\section{Conclusions}

Anatase $\mathrm{TiO}_{2}$ is considered to be the active photocatalytic component based on charge carrier dynamics, chemical properties and the activity of photocatalytic degradation of organic compounds. In our work, we demonstrated that selenium doped titania nanoparticles may improve the photocatalytic performances of $\mathrm{TiO}_{2}$ nanoparticles, with possible application in degradation of the organic dyes and pollutants in wastewater. The fabrication and structural characterization of $\mathrm{TiO}_{2}$ and Se-doped $\mathrm{TiO}_{2}$ nanoparticles was presented in our study, including analysis of FTIR spectroscopy, XRD diffraction pattern and SEM morphological details. We assume that high photocatalytic activity of $\mathrm{SeTiO}_{2}$ nanoparticles is due to the synergistic effects of higher surface area, lower crystal size and higher dopant content.

\section{References}

1.GUPTA, S.M., TRIPATHI, M. Chinese Sci. Bull., 56, 2011, p. 1639.

2.YU, J., FAN, J., LV, K. Nanoscale 2, 2010, p.2144.

3.WU, X., CHEN, Z., LU, G.Q., WANG, L. Adv. Funct. Mater. 21, 2011, p.4167.

4.ATANDA, L., MUKUNDAN, S., SHROTRI, A., MA, Q., BELTRAMINI, J. Chem. Cat. Chem. 7, 2015, p.781.

5.XU, H., CARLUCCI, C., SCREMIN, B.F., GIANNINI, C., SIBILLANO, T., SCRASCIA, A., CAPODILUPO, A.L., GIGLI, G., CICCARELLA, G. J. Nanoeng. Nanomanuf., 4, 2014, p. 28.

5.CHEN, X.B., MAO, S.S. Chemical Reviews, 107, nr.7, 2007, p. 2891.

6RUPP, F., HAUPT, M., KLOSTERMANN, H., KIM, H.S., EICHLER, M., PEETSCH, A., SCHEIDELER, L., DOERING, C., OEHR, C., WENDEL, H.P., SINN, S. DECKER, E., vonOHLE, C., GEIS-GERSTORFER, J. Acta Biomater., 6, 2010, p.4566.

7.MATSUNAGA, T., TOMATO, R., NAKAJIMA, T., WAKE, H. FEMS Microbio. Lett., 29, 1985, p. 211.

8.HORIE, M., SUGINO, S., KATO, H., TABEI, Y., NAKAMURA, A., YOSHIDA, Y. Toxicol. Mech. Methods., 26, nr. 4,2016 p.284.

9.MENG, N., LEUNG, M.K.H., LEUNG, D.Y.C., SUMATHY, K. Renew. Sust. Energ. Rev., 11, 2007, p. 401.

10. WANG, J., LI, R.H., ZHANG, Z.H., SUN, W., WANG, X.F., XING, Z.Q., XU, R., ZHANG, X.D. Inorg. Mater, 44, 2008 , p. 608. 
11.CONG, Y., ZHANG, J.L., CHEN, F., ANPO, M., HE, D. J. Phys. Chem. C., 111, 2007, p.10618.

12.ZHANG, S.Y., CHEN, X. J., TIAN, Y. P., JIN, B. K., YANG, J. X. J. Journal of Crystal Growth 304, 2007, p.42.

13. ROCKAFELLOW, E.M., HAYWOOD, J. M., WITTE, T., HOUK, R. S., JENKS, W. S. Langmuir, 26, 2010 , p.19052.

14.XIE, W., RUI, L.I., XU, Q., Scientific Reports 8, 2018, p. 8752.

15.ZAVALA, M.Á.L., MORALES, S.A.L., ÁVILA-SANTOS, M. Heliyon, 3, nr. 11, 2017, p. 1

16.LIU, W. GOLSHAN, N.H., DENG, X., HICKEY, D.J., ZEIMER, K., LI, H., WEBSTER, T.J. Nanoscale, 8, nr. 34, 2016 , p. 15783.

17.CAVAlU, S., KAMEL, E., LASLO, V., FRITEA, L., COSTEA,T., ANTONIAC, I.V. EUGENIU, V., ANTONIAC, A., SEMENESCU, A., M18.HAN, A., SACELEANU, V., VICAS, S., REV.CHIM.(Bucharest), 68, no. 12, 2017, p.2963.

19.CAVALU, S., ANTONIAC, I.V., FRITEA, L., MATES, I.M., MILEA, C., LASLO, V., VICAS, S., MOHAN, A., J. Adhes. Sci. Technol., 32, nr. 22, 2018, p. 2509.

20.PRAVEEN, P., VIRUTHAGIRI, G., MUGUNDAN, S., SHANMUGAM, N. Spectrochim. Acta A Mol. Biomol. Spectrosc. 117, 2014, p. 622. 21.REFAT, M. S., ELSABAWY, K. M., Bull. Mater. Sci., 34, 2011, p. 873.

22.POUDEL, B., WANG, W.Z., DAMES, C., HUANG, J.Y., KUNWAR, S., WANG, D.Z., BANERJEE, D., CHEN, G., REN, Z. F. Nanotechnology, 16, 2005, p.1935.

23.CHENARI, H.M., SEIBEL, C., HAUSCHILD, D., REINERT, F., \& ABDOLLAHIAN, H. Materials Research, 19, nr. 6, 2016, p. 1319.

24.KASSAHUN, S., KIFLIE, Z., SHIN, D., PARK, S. J. Water Environ. Nanotechnol., 2, nr. 3, 2017, p.136.

Manuscript received: 24.04.2019 